Birgit Haustedt - Die Kunst der Verführung 


\section{Birgit Haustedt}

\section{Die Kunst der Verführung}

Zur Reflexion der Kunst im Motiv der Verfühnung bei Jean Paul, E. T. A. Hoffmann, Kierkegaard und Brentano

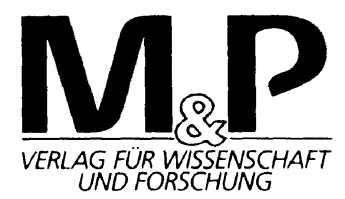


Die Deutsche Bibliothek - CIP-Einheitsaufnahme

\section{Haustedt, Birgit:}

Die Kunst der Verführung : zur Reflexion der Kunst im Motiv der Verführung bei Jean Paul, E. T. A. Hoffmann, Kirkegaard und Brentano / Birgit Haustedt. - Stuttgart : M und P, Verl. für Wiss. und Forschung, 1992

Zugl.: Hamburg, Univ., Diss., 1991

ISBN 978-3-476-45011-1

ISBN 978-3-476-45011-1

ISBN 978-3-476-04169-2 (eBook)

DOI 10.1007/978-3-476-04169-2

Dieses Werk ist einschließlich aller seiner Teile geschützt. Jede Verwertung außerhalb der engen Grenzen des Urheberrechtsgesetzes ist ohne Zustimmung des Verlages unzulässig und strafbar., Das gilt insbesondere für Vervielfältigungen, Übersetzungen, Mikroverfilmungen und Einspeicherung in elektronischen Systemen.

M \& P Verlag für Wissenschaft und Forschung ein Verlag der J. B.Metzlerschen Verlagsbuchhandlung und Carl Emst Poeschel Verlag GmbH in Stuttgart

(c) 1992 Springer-Verlag GmbH Deutschland Ursprünglich erschienen bei J. B. Metzlersche Verlagsbuchhandlung und Carl Ernst Poeschel Verlag GmbH in Stuttgart 1992 


\section{Inhaltsverzeichnis}

I. Roquairol: Der Verführer als Künstler

II. E.T.A. Hoffmanns "Don Juan"

Der Erzähler und die Figuren der Oper

Hoffmanns Erzählverfahren: Verführung zur Kunst

Hoffmanns Erzählung und die Tradition

des Don-Juan-Stoffes

III. Kierkegaard: "Das Musikalisch-Erotische"

Geist versus Sinnlichkeit - Die historische Ableitung

Sinnlichkeit in der Kunst

59

Die Verführung

Das Darstellungsverfahren

IV. Kierkegaard: "Das Tagebuch des Verführers"

Das Motto

Das Thema

1. Kunst als Metapher der Verführung $\quad 89$

Die Offenbarung des Schönen $\quad 89$

Genuß und Selbstbeherrschung $\quad 92$

Das Interessante $\quad 96$

Müßiggänger und Flaneur $\quad 100$

$\begin{array}{ll}\text { Der Blick } & 105\end{array}$

Die Rolle der Schrift $\quad 110$

Das Hervorbringen von Bedeutungen 113

Die Verführung als Theaterinszenierung 118

Das Gewebe des Textes 124 
2. Verführung als Metapher der Kunst 126

Verführung als Prozeß $\quad 128$

Verführung und Krieg $\quad 130$

Der Blick und das Schreiben $\quad 135$

Der künstlerische Prozeß 139

Die Funktionen des Weiblichen $\quad 141$

3. Die Verführung des Lesers -

Zum Schreibverfahren Kierkegaards 158

Herausgeber und Leser $\quad 158$

$\begin{array}{ll}\text { Tagebuchform und Briefroman } & 168\end{array}$

V. Ein erotischer Brief:

Clemens Brentano an Karoline von Günderrode

179

$\begin{array}{lr}\text { Anhang } & 215\end{array}$

Forschungsbericht zu Kapitel II (Hoffmann) 216

Forschungsbericht zu Kapitel IV (Kierkegaard) 225

Forschungsbericht zu Kapitel V (Brentano) 237

Anmerkungen zu Kapitel I $\quad 248$

Anmerkungen zu Kapitel II $\quad 251$

Anmerkungen zu Kapitel III $\quad 260$

Anmerkungen zu Kapitel IV $\quad 264$

$\begin{array}{ll}\text { Anmerkungen zu Kapitel V } & 275\end{array}$

$\begin{array}{ll}\text { Literaturverzeichnis } & 283\end{array}$ 